\section{REFERENCES}

1. Ryan M, Stephen J. General practitioners and family doctors in the Russian Federation. Br J Gen Pract 1996; 46: 487-489

2. Earl-Slater A. Health care reforms in the Czech Republic. J Manag Med 1996; 10: 13-22.

3. Toon P. Reforming the Russian Health Service. BMJ 1998; 317: 741-744.

4. Healthcare for London. Consulting the capital. London, 2007.

http://www.healthcareforlondon.nhs.uk/background. asp (accessed 8 Aug 2008).

5. Rese A, Balabanova D, Danishevski K, McKee M. Implementing general practice in Russia: getting beyond the first steps. BMJ 2005; 331: 204-207.

6. Ministry of Health of Russian Federation. Decree \# 237: Stepwise transition of outpatient services to general practice model. Moscow: 1992

7. Danishevski K, Balabanova D, McKee M, Atkinson S The fragmentary federation: experience with the decentralized health system in Russia. Health Policy Plan 2006; 21:183-194.

8. Fister K, McKee M. Health and healthcare in transitional Europe. BMJ 2005; 331: 169-170.

9. Horder J. The College in my practice. Br J Gen Pract 1992; 42: 126-128.

10. Gibbs T, Mulka O, Zaremba E. The Royal College of General Practitioner's Fellowship Scheme 1993-1997. Eur J Gen Pract 1998; 4: 84-87.

11. Gibbs T, Mulka O, Zaremba E, Lysenko G. Ukrainian general practitioners: the next steps. Eur I Gen Pract 1999; 5: 33-36.

12. Culture of Ukraine.

http://www.everyculture.com/To-Z/Ukraine (accessed 4 Aug 2008)

13. World Health Organisation. The European health report 2005. WHO: Geneva, 2005. http://www.euro.who.int/ehr2005 (accessed 8 Aug 2008)

14. Scottish Intercollegiate Guideline Network. NHS Quality Improvement Scotland, 2001. http://www.sign.ac.uk (accessed 4 Aug 2008).

15. National Institute for Health and Clinical Excellence. NICE: London, 2007. http://www.nice.org.uk (accessed 4 Aug 2008)

16. Vovk I. The importance of family planning in Ukraine. In: Johannisson E, Kovacs L, Resch BA, et al (eds). Assessment of research and service needs in reproductive health in Eastern Europe - concerns and commitments. New York, Parthenon Publishing Group, 1997: 217-218.

17. Alliance. Supporting community action on AIDS in Europe. http://www.aidsalliance.org (accessed 4 Aug 2008).

18. Godlevsky AG. Youth mental health and development of community mental healthcare services in Ukraine. European Psychiatry 1998; 13(4): 250.

19. Furtak I. A beginning of family medicine practice in Ukraine. Annu Meet Int Soc Technol Assess Health Care Int Soc Technol Assess Health Care Meet. 1997; 13: 150.

20. World Health Organisation and UNICEF. Primary health care: report of the International Conference on Primary Health Care, Alma-Ata USSR. Geneva: WHO, 1978.

21. World Health Organisation. Health for all in the 21st century. Geneva: World Health Organisation, 1998

DOI: 10.3399/bjgp08X342066

\title{
The call of general practice beckons
}

The time of the year when our health service was at greatest risk of being thrown into chaos has thankfully passed. Newly-qualified interns have commenced work as doctors for the first time, fresh from that blissful 6 weeks between passing final medical exams and starting the new job. Short straws were drawn, meaning some of them started their careers on call at a weekend; always a dreaded prospect which at least a quarter of us have experienced. In addition to this, newly-appointed registrars in all specialties took up new posts with considerably more responsibility. This situation coupled with the skeletal or sometimes nonexistent ancillary medical services at weekends, particularly in the smaller hospitals all adds to the stress. My colleagues and I in the third year of the Western Area GP training programme have left all this behind, no more bleeps, no more continuous 36-hour shifts every fourth or fifth night and no more having to be in two places at once. Yes, we have left the rocky terrain of hospital life for the greener pastures of general practice.

The popularity of a career in general practice has increased enormously over the past few years. This is clearly reflected in the strong competition for places on the vocational training programmes. Most interns now wish to pursue this specialty where as recently as 4 years ago only half of my graduating class were even considering it. The appeal of life as a GP has also increased considerably over the past decade. General practice has revolutionised itself in many ways. The organisation of out-of-hours cooperatives and the appointment system are probably the most notable. All of this has enhanced the appeal of working in the community and providing continuity of care. The really fantastic feature of general practice is that it is all about interacting with people and building lifelong relationships that cross generations. Most interaction in a hospital is between staff whereas the opposite is the case in the community. The variety of medical issues that arise in general practice simply cannot be matched in any other specialty, from signing certs to thromblysing in the community means no 2 days are the same. The vast majority of medical consultations in Ireland take place in GP surgeries and most medical conditions are successfully managed in this setting.

My colleagues and I have completed 2 years of hospital posts in addition to our intern year. The rotation consists of psychiatry, A\&E, obstetrics and gynaecology, medicine, and paediatrics, all very necessary for working in the community. The pace of life in Irish hospitals, particularly the smaller ones has increased enormously over the past number of years, the demands placed on them particularly in the winter months are huge. Most of us will not miss the long shifts with little or no sleep. It was with a light heart I turned in my bleep to the busy hospital switchboard receptionist, never to hold it again, that small but loud creature that resided on my belt for the past 6 months whose shrill wail is indelibly marked on my brain forever, its call guaranteed to increase blood pressure and heart rate simultaneously. The European Working Time Directive has largely remained aspirational in the smaller hospitals. The workload, particularly when on call is likely to remain onerous for the foreseeable future.

It has not been all negative in the hospital posts. We will all miss the camaraderie of other colleagues and the whole social aspect to being a member of hospital staff; there was always some excuse for a night out. I suspect we will find working alone, particularly in the out-of-hour's situation, a big challenge. In the hospital there is always somebody to consult if in doubt. Some of us may find working in rural areas lonely and emergencies in this setting can be truly stressful especially if you are the only doctor for a 30 mile radius. It is hard to beat the small country hospital in terms of learning because you are at the coalface when on call. There is no quicker way to learn than on your feet in an emergency situation. I have had the privilege of working with some truly dedicated, brilliant people who were always willing to teach.

Overall the hospital experience has been great, particularly in terms of learning. We have emerged battle hardened and hopefully have gained adequate experience to serve our patients in the community well.

\section{Robert Marsh}

DOI:10.3399/bjgp08X342075 